\title{
Anatomical Variations of the Celiac Artery Detected by Multidecteor Computated Tomography
}

\author{
Medhat M. Refaat, 2. Shorouk Z. AbdelShafy, Maha M. Hassan
}

\begin{abstract}
Department of diagnostic and interventional radiology, Benha faculty of medicine, Banha University, Egypt.

Correspondence to: Maha M. Hassan. Department of diagnostic and interventional radiology, Benha faculty of medicine, Banha University, Egypt.
\end{abstract}

Email:

dodi_29_11@yahoo.com

Received: 22 June 2021

Accepted: 26 November 2021

\begin{abstract}
Background: Multi detector computed tomography (MDCT) is form of computed tomography technology for diagnostic imaging for diagnosis of celiac trunk variations. Purpose: This study aims to describe the main anatomical variations of the celiac artery and its branches using Multi detector computed tomography. Patients and Methods: This study included 30 patients with signs and symptoms of various liver and other abdominal pathologies in which biphasic or triphasic contrastenhanced CT was indicated (to study early arterial phase). Results: The commonest variant in our study was Uflacker type II (hepato-splenic trunk) in which CHA and SA have common trunk and LGA arises separately from aorta representing $40 \%$ while Uflacker type V (gastro-splenic trunk) in which the origin of the CHA from either the SMA or the aorta was the second common variants representing $20 \%$.
\end{abstract}

Conclusion: Knowledge of the celiac trunk anatomical variants is very important presurgical, pre-laparoscopic or even pre-interventional and this can be achieved using MDCT to minimize and avoid the major vascular complications and decrease the morbidity of patients , late arterial phase of computed tomography is sufficient for assessing celiac trunk variants.

Keywords: Anatomical variation; Celiac trunk; MDCT

\section{Introduction:}

Celiac artery, also known as the celiac axis or celiac trunk, is a major visceral artery in the abdominal cavity. The celiac trunk arises at the level of the aortic hiatus of the diaphragm, anterior to 12th thoracic, 1th lumbar intervertebral space. It gives off the three main branches, which supply the structures derived from the foregut ${ }^{(1)}$.

It is typically a short vessel that passes underneath the median arcute ligament, 
often indented on its superior surface by this ligament, and then courses anteriorly or slightly antero-laterally in the lesser sac. Classic branching of the celiac artery into the left gastric artery, splenic artery, and common hepatic artery is seen in approximately $70 \%$. Variations are present in approximately $30 \%$. In general, any of the three celiac branches may arise independently from the aorta or superior mesenteric artery, or the celiac artery may give rise to other branches ${ }^{(2)}$

In the recent decades, with the advent of interventional and surgical options for patients with partial hepatectomy for liver transplantation, end-stage hepatic malignancy, and determining tumor respectability in patient with pancreatic and hepatobiliary malignancy, surgeons, and interventional radiologist are dependent on accurate imaging before procedures. ${ }^{(3)}$

Multi detector computed tomography (MDCT) is form of computed tomography technology for diagnostic imaging. In MDCT, a two-dimensional array of detector elements replaces the linear array of detector elements used in typical conventional and helical CT scanners. The two-dimensional detector array permits CT scanners to acquire multiple slices or sections simultaneously and greatly increase the speed of CT image acquisition. Image reconstruction in
MDCT is more complicated than that in single section CT. ${ }^{(4)}$

Digital subtraction angiography (DSA) is regarded as the gold standard in the evaluation of vascular structures, although its invasive nature significantly limits its role. In recent years, the introduction of multi detector CT and its ability to image vascular structures of small diameter have led to a significant reduction in the utilization of invasive DSA examinations. (5)

\section{Patients and methods:}

This was a cross-sectional which included 30 patients with signs and symptoms of various liver and other abdominal pathologies in which biphasic or triphasic contrast-enhanced CT was indicated (to study early arterial phase). Their ages ranged from 24 to 63 years (17 males and 13 females). This study was done in radiology department in Benha University hospital, during the period from June 2020 to April 2021. The study was approved by the institutional ethics committee. Study was done in Banha university department of diagnostic and interventional radiology

\section{Exclusion criteria:}

- Patient with contraindication to abdominal enhanced contrast computed tomography scan such as: 
- Contraindications for the use of contrast media:

Allergy to iodine

Patient with history of abdominal operation that may change vascular anatomy such as bariatric operation

Patient with multiple congenital anomalies

Patient refused to undergo CT examination

Toxic goiter of the thyroid

Planned radioiodine treatment of thyroid cancer

Pregnant women

Persons with major complications after the previous administration of a contrast medium

Persons with hepatic and renal failure

\section{MDCT technique:}

Technique: the patient will be in supine position with timing bolus technique used. Scan direction will be craniocaudal in all patients. Scout was taken starting from above the level of the diaphragm down to the pelvis.

\section{Contrast media:}

We used $80 \mathrm{ml}$ non-ionic iodinated contrast media injected via injector at a rate of $4-5 \mathrm{ml} / \mathrm{s}$.

\section{Image processing:}

The axial images were transferred to the work station where multi-planar reformatted images (MPR) were done as well as Maximum intensity projection (MIP), and 3D volume rendering (VR) images were also processed.

\section{Possible Risk:}

- Risk of exposure to contrast side effects such as hypersensitivity reactions, contrast induced thyroid dysfunction \& contrast induced nephropathy.

- Risk of exposure to radiation side effects such as dry mouth, sore throat, local edema \& stiffness.

\section{Statistical analysis:}

Data management and statistical analysis were done using SPSS vs.25. (IBM, Armonk, New York, United states).Numerical data was summarized as means and standard deviations or medians and ranges. Categorical data was summarized as numbers and percentages.

\section{Results:}

This study included 30 patients 17 female (56.7\%) and 13 male (43.3\%) Fig: (1), regarding in age between 24 and 63 years (mean age: $38.15+8.2$ ). 
Table (1).

The commonest variant in our study was Uflacker type II (hepato-splenic trunk) in which CHA and SA have common trunk and LGA arises separately from aorta representing $40 \%$ while Uflacker type V (gastro-splenic trunk) in which the origin of the CHA from either the SMA or the aorta was the second common variants representing 20\%. Table (2).

\section{Cases}

Case 1:CT male patient 29 years old type VI classification of non-classic variant of celiac trunk (celiac-mesenteric): Axial cut of multi-detector CT in early arterial phase shows that celiac and mesenteric trunk have common origin from aorta .Sagittal cut at multi-detector CT image showing celiac-mesenteric trunk arise from aorta and divide into celiac and mesenteric trunk Fig. $(2,3)$

\section{Case 2}

CT male patient 61 years old type II classification of non-classic variant of celiac trunk (hepato-splenic):Axial cut of multi-detector CT in early arterial phase shows that LGA arises from directly from aorta and celiac trunk divided into $\mathrm{CHA}$ and splenic artery .Sagittal cut at multidetector CT image showing LGA arise directly from aorta .Fig. $(4,5)$.

Table 1: demographic distribution of the study group.

\begin{tabular}{llc}
\hline & Variables & $\begin{array}{c}\text { Patients } \\
(\mathbf{n = 3 0})\end{array}$ \\
\hline $\begin{array}{l}\text { Age (years) } \\
\bullet \quad \text { Mean } \pm \text { SD }\end{array}$ & & $38.15 \pm 8.2$ \\
Range & Male & $24-63$ \\
Sex, $(\%)$ & Female & $17(56.7 \%)$ \\
BMI $\left(\mathrm{kg} / \mathrm{m}^{2}\right)$ & & $13(43.3 \%)$ \\
$\bullet \quad$ Mean \pm SD & & $26.02 \pm 2.82$ \\
$\bullet \quad$ Range & & $23.7-29.2$ \\
\hline
\end{tabular}


Table (2) histopathological classification of the study group

\begin{tabular}{lcc}
\multicolumn{1}{c}{ Types } & \multicolumn{2}{c}{$\begin{array}{c}\text { Patients } \\
(\mathbf{n = 3 0 )}\end{array}$} \\
& $\mathbf{N}$ & \% \\
\hline Type I = no classic variant & 3 & 10 \\
Type II = hepato- splenic trunk & 12 & 40 \\
Type III = hepato- gastric trunk & 3 & 10 \\
Type IV =hepato-spelno mesenteric trunk & 0 & 0 \\
Type V = gastro- splenic trunk & 6 & 20 \\
Type VI = celiaco-mesenteric trunk & 3 & 10 \\
Type VII = celiaco- colic trunk & 0 & 0 \\
Type VIII = no celiac trunk & 3 & 10 \\
\hline
\end{tabular}

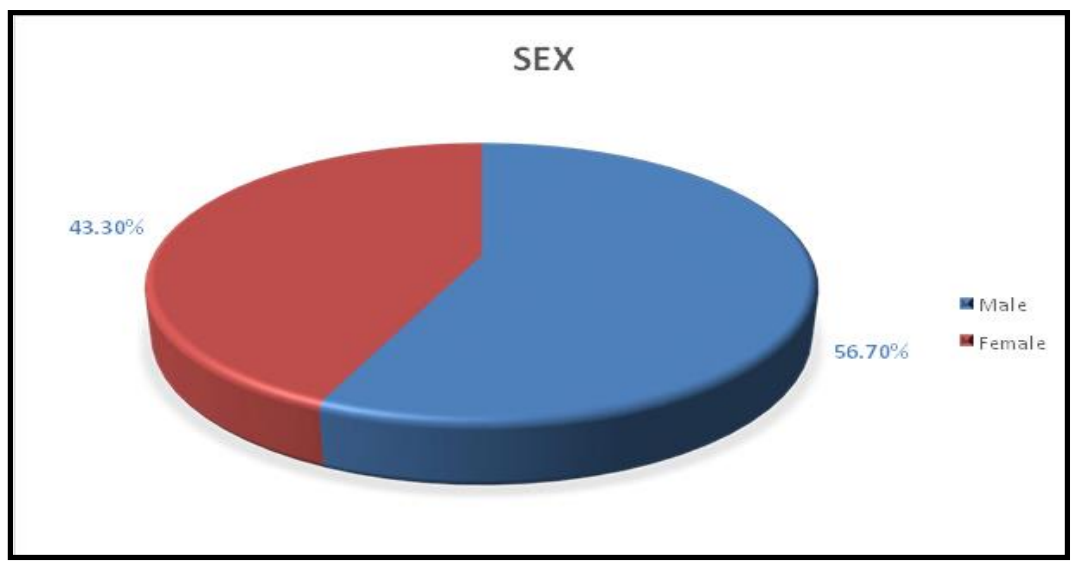

Figure 1: Sex distribution of the study group.

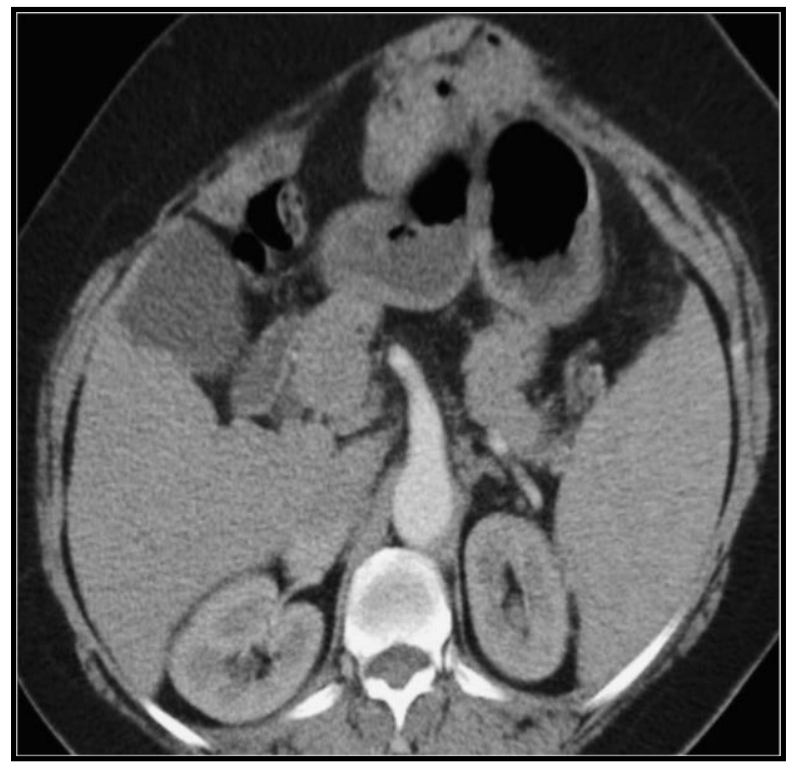

Figure 2: case 1 


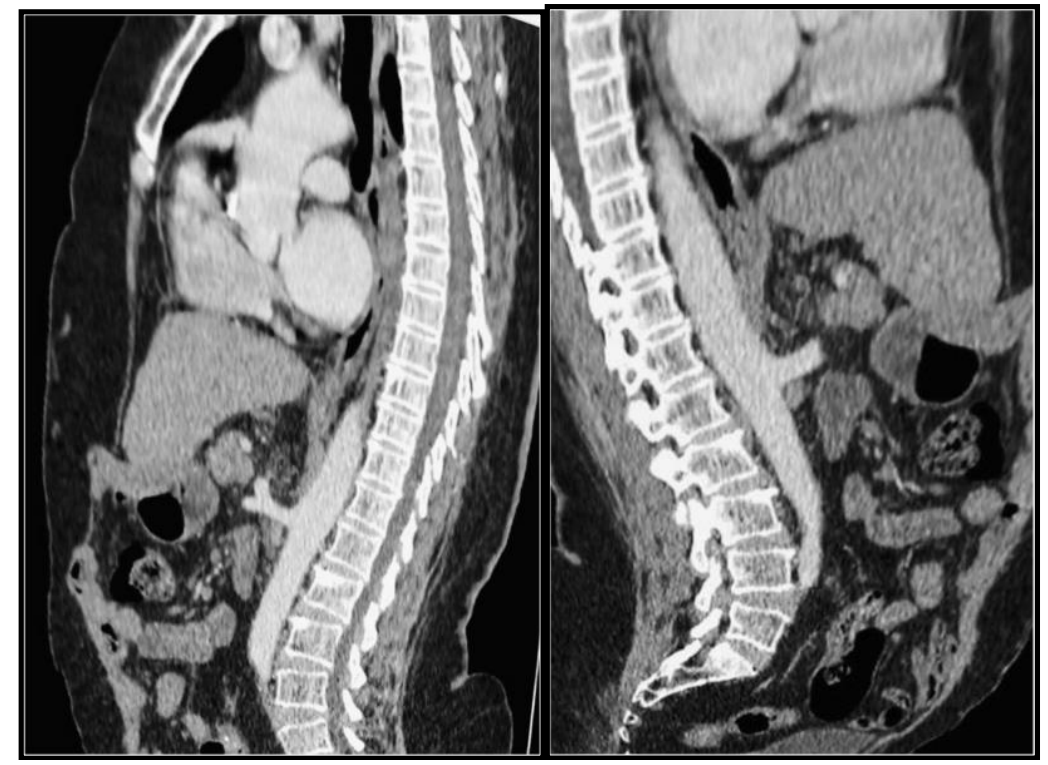

Figure 3: case 1

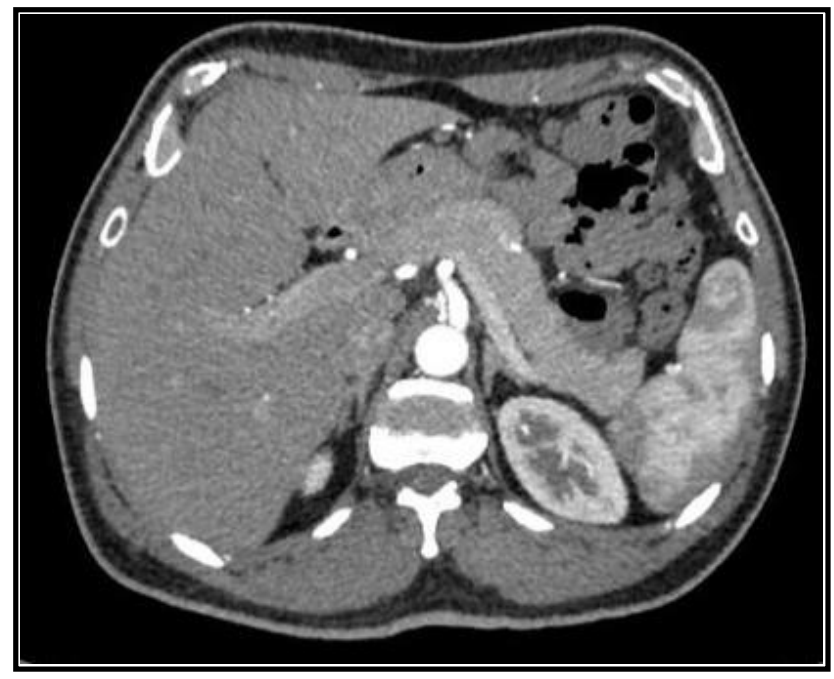

Figure 4 : case 2

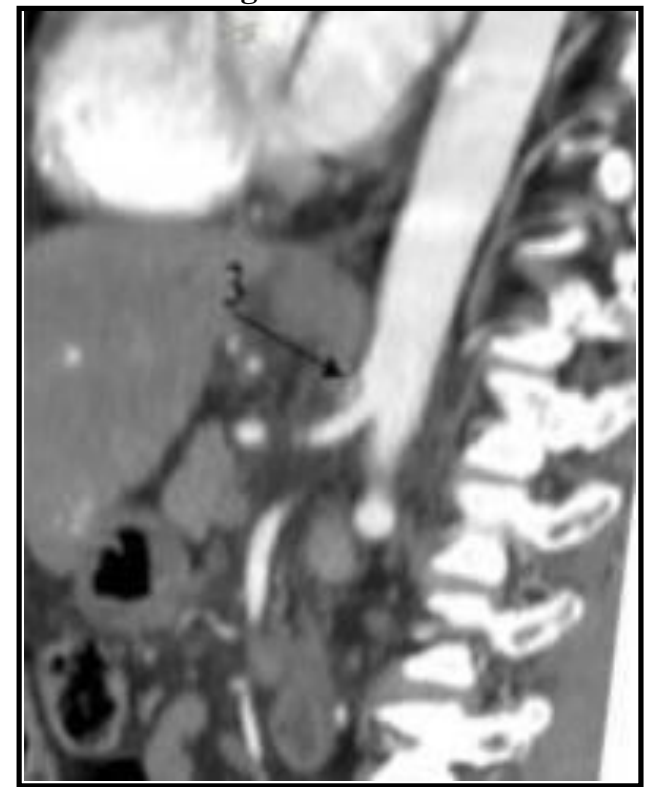

Figure 5:case 2 


\section{Discussion:}

Various studies and authors tried to classify the celiac trunk anomalies and variants based on the branching pattern.

First classification was done in 1917 by Lipshutz, while the most recent one was done by Uflacker in 1997 classifying the celiac trunk into eight types.

This study aimed to examine the frequencies of variations in branching pattern of coeliac trunk in our study population, in the hope that knowledge of these variations would help clinicians to minimize the chances of serious complications during laparoscopic and interventional procedures for the treatment of benign and malignant disease originating from the foregut and midgut as well as liver transplantation surgeries and aortic vascular surgeries. ${ }^{(6)(7)}$

Similar to other studies, the mean age of patients in our study was 38 years which is close to the mean age of other studies (42 years) ${ }^{(8)}$ and (49 years) ${ }^{(4)}$. This age of diagnosis is related to the age where people suffer more from hypertension, aortic aneurysms, renal hypertension and chronic liver disease, so is exposed more to diagnostic images as CT. No statistical significant differences regarding sex was found. ${ }^{(8)}$

The commonest variant in our study was Uflacker type II (hepato-splenic trunk) in which CHA and SA have common trunk and LGA arises separately from aorta representing $40 \%$ while Uflacker type V (gastro-splenic trunk) in which the origin of the CHA from either the SMA or the aorta was the second common variants representing $20 \%$ and this is similar to Iezzi et al., Mburu et al., and Lipschutz.

Many studies showed that Uflacker type I which is the classic trifurcation is the commonest form.

A study in 2016 found $90.5 \%$ of population with type I classification and $9.5 \%$ with other variations. ${ }^{(9)}$

Another study found $83.9 \%$ of population with type I classification and $16.1 \%$ with other variations. ${ }^{(10)}$

Other researchers found $79.1 \%$ of population with type I classification and $20.9 \%$ with other variations. ${ }^{(11)}$

Another study found $89.1 \%$ of population with type I classification and $10.1 \%$ with other variations. ${ }^{(12)}$ 
Other researchers Ramanand et al. found $9 \%$ of his patients with celiac trunk anatomical. ${ }^{(13)}$

A previous study found $94.5 \%$ of population with type I classification and $5.5 \%$ with other variations. ${ }^{(14)}$

Another study, found $90.2 \%$ of population with type I classification and $9.8 \%$ with other variations. ${ }^{(15)}$

\section{Conclusion:}

Knowledge of the celiac trunk anatomical variants is very important pre-surgical, pre-laparoscopic or even preinterventional and this can be achieved using MDCT to minimize and avoid the major vascular complications and decrease the morbidity of patients, late arterial phase of computed tomography is sufficient for assessing celiac trunk variants.

\section{References:}

1- Hiatt JR, Gabbay J and Busuttil RW. (1994): Surgical anatomy of the hepatic arteries in 1000 cases. Ann Surg 220:50-52.

2- Marco-Clement I, Martinez-Barco A, Ahumada N, Ples A , Adam P, Drop A et al. (2016): Anatomical variations of the celiac trunk: cadaveric and radiological study .Surg Radiol Anat:; 38(4):501-10.

3- Catalano OA, Singh AH, Uppot RN, NunoGuzman, C. M., Gonzalez-Gonzalez, M. E., et al.
(2008) : Vascular and biliary variants in the liver: Implications for liver surgery. Radiographics. 2008; 28:359-78.

4- Ugurel MS, Battal B, Bozlar U, Halpern EF, JordanPF , Thrall JH et al. (2010): Anatomical variations of hepatic arterial system, celiac trunk and renal arteries: an analysis with multidetector CT angiography. Br J Radiol 83:661-667.

5- Munshi IA, Fusco D, Tashjian D, Halpern EF, JordanPF and Thrall JH, el al. (2000) : Occlusion of an aberrant right hepatic artery, originating from the superior mesenteric artery, secondary to blunt trauma. J Trauma

6- Kimura W, Han I, Furukawa Y, Markabaoui K, Tamburrini O , Salvatore M et al., (1997): Appleby operation for carcinoma of the body and tail of the pancreas. Hepatoga-stroenterology; 44:387-93.

7- Rela M, McCall JL, Karani J, Duarte CM, Borges RF, Magalhães AG ,et al., (1998): Accessory right hepatic artery arising from the left: implications for split liver transplantation. Transplantation; $66: 792-4$.

8- Khan RN, Ali M, Sadiq M, and Hasan N. (2017): Detecting Anatomical Variations of Coeliac Trunk Branching Pattern in the Population of Karachi Using 3D Multidetector Computed Tomographic Angiography (MDCTA) [Online]. Annals ASH KMandDC; 22:262-69.

9- Osman A, and Abdrabou A. (2016): Celiac trunk and hepatic artery variants: A retrospective preliminary MSCT report among Egyptian patients .The Egyptian Journal of Radiology and Nuclear Medicine 47: 1451-1458. 
10- Rao, A. H., Thahim, H., and Khan, R. (2018): Variation assessment of coeliac trunk branching pattern in changed bowel habits, abdominal pain and kidney/adrenal pathologies patients. indo american journal of pharmaceutical sciences, 5(8), 7280-7287.

11- Koops A, Wojciechowski B, Broering DC, Fleischmann D, Hallett RL, Rubin GD, et al., (2004): Anatomic variations of the hepatic arteries in 604 selective celiac and superior mesenteric angiographies. Surg Radiol Anat.;26:239-44.

12- Song SY, Chung JW, Yin YH, Rydberg J, Liang Y ,Teague SD , et al., (2010): Celiac axis and common hepatic artery variations in 5002 patients: systematic analysis with spiral CT and DSA. Radiology.;255:278-88.
13- Ramanand, G., Singh, C. A., Rana, C. K., Ramesh, K., Singh, S. I. (2018): 64 Slice CT Evaluation of Anatomical Variations of Main Arteries Arising from the Abdominal Aorta and their Branching Pattern. JMSCR Volume 06 Issue 05 ,pp 576-88

14- Sureka B, Mittal M, Mittal A, Buell J., Tranchart H., Cannon R , et al., (2013): Variations of celiac axis, common hepatic artery and its branches in 600 patients. Indian J Radiol Imaging; 23:223-33.

15- Caliskan, E., Acar, T., Ozturk, M., Bayramoglu, Z., Yilmaz, R., Elbuken, F.,et al. (2018): Celiac trunk and common hepatic artery variations in children: an analysis with CT angiography. Folia morphologica. Vol 77(4) pp:67

To cite this article: Medhat M. Refaat, Shorouk Z. AbdelShafy, Maha M. Hassan. Anatomical Variations of the Celiac Artery Detected by Multidecteor Computated Tomography. BMFJ 2022; 39 (Radiology):98-106. DOI: 10.21608/bmfj.2021.81963.1431 
Variations of the Celiac Artery, 2022 